\title{
Acute colitis in a district general hospital
}

\author{
H W JONES, J GROGONO, A M HOARE
}

\begin{abstract}
A review of all patients who had been admitted to hospital with acute ulcerative colitis in one health district between 1975 and 1984 showed that 96 had required 114 admissions with acute colitis: $42 \%(40)$ were admitted during their first attack, and $20 \%$ (19) required urgent surgery. A further nine patients underwent surgery after responding initially to intensive medical treatment that did not check the attack. There were no deaths from acute colitis. Thirteen patients underwent elective surgery for ulcerative colitis, and there were no deaths. The prognosis for acute colitis in district general hospitals has improved.
\end{abstract}

\section{Introduction}

The mortality from ulcerative colitis reported from district hospitals is high compared with that reported from teaching centres in the United Kingdom. In 1971 Ritchie reported a mortality rate of $52.2 \%$ for emergency surgery in non-teaching hospitals of the (then) North East Metropolitan Hospital Region between 1955 and 1966 compared with a mortality rate of $30.8 \%$ in teaching hospitals of the same region. ${ }^{1}$ No deaths occurred among 100 patients who were admitted with severe colitis in Oxford. ${ }^{2}$ A review of acute colitis in district hospitals in the United Kingdom covered the period from 1975 to 1977 in 22 district hospitals and two teaching centres. ${ }^{3}$ There were no deaths during medical or surgical treatment of acute colitis in the two specialist units, but in the district hospitals the

\footnotetext{
Wycombe General Hospital, High Wycombe, Bucks

H W JONES, MD, MRCP, senior registrar

J GROGONO, FRCS, consultant surgeon

A M HOARE, MD, FRCP, consultant physician

Correspondence to: Dr Hoare.
}

overall mortality rate was $4.5 \%$, with a $20 \%$ rate in patients who underwent urgent surgical treatment. In a more recent survey of district hospitals (1977-81) Ritchie et al found that the mortality rate after surgery for acute colitis was still $24 \% .{ }^{4}$ The mortality in district hospitals may now have fallen, and so we reviewed the outcome in all patients who were admitted with acute colitis and patients with colitis who were admitted for elective surgery in one health district over a 10 year period.

\section{Method}

The histology reports of all rectal biopsy specimens and large bowel resections that were undertaken between 1 January 1975 and 31 December 1984 were reviewed. The notes of all patients with possible ulcerative colitis were obtained and the clinical histories and relevant investigations reassessed. To ensure that all patients with ulcerative colitis who were managed in the district were included the list was checked against the disease indexes of individual physicians and against the hospital disease index. The details of investigations, management, and complications were recorded.

The diagnosis of ulcerative colitis was accepted on a consistent clinical history, characteristic sigmoidoscopic appearances, histological changes in the rectal biopsy specimen, and radiological investigations. Patients who had definite Crohn's colitis were excluded, but those who had colitis that was indeterminant between Crohn's and ulcerative colitis were included. Patients who were admitted with severe colitis were treated with a standard regimen as described by Truelove and Jewell ${ }^{5}$ except that antibiotics were not given.

\section{Results}

Patients-Three hundred and thirteen patients with ulcerative colitis or indeterminant colitis were seen in the district between January 1975 and December 1984; 307 patients were traced by reviewing the histology reports of 978 rectal biopsy specimens and a further six found after reviewing physicians' disease indexes. No further patients were found in the hospital index. The extent of the disease was established at diagnosis by barium enema examination in 259 patients, by barium enema examination and 
colonoscopy in 30 , and by sigmoidoscopy alone in 17 . The remaining seven patients all presented acutely and underwent surgery without contrast examination.

Acute colitis-Ninety six patients required 114 admissions with acute colitis. Eighty three patients were admitted once, 10 patients twice, two patients three times, and one patient five times. Thirty five patients had all the criteria of a severe attack as defined by Truelove and Witts, ${ }^{6}$ and seven had toxic megacolon. The remainder had had bad attacks with some but not all of the criteria of a severe attack. No patients were admitted with colonic perforation. The average age of the patients was 48 years (range 13-93 years). Twenty seven (28\%) patients were over 60 when admitted, and $40(41 \%)$ were admitted with a first attack. Medical treatment resolved the acute attack in $86(80 \%)$ admissions. Twenty eight patients required surgery as a result of admission with an acute attack of colitis.

Surgery-The table gives details of the operations performed and the indications for surgery. No patients died after emergency or elective surgery for acute colitis-alone. Two patients died soon after having palliative subtotal colectomy for inoperable obstructive carcinomas complicating colitis. Seven patients had early complications of surgery, all of whom fully recovered: pelvic abscess (two), subphrenic abscess (one), pulmonary embolus (one), our study but still showed a $24 \%$ mortality rate for surgery for acute colitis. ${ }^{4}$ It is possible that each of their 10 hospitals operated on one patient with acute colitis every year compared with nearly two patients a year in our district. This may have increased the awareness of acute colitis. We agree with Ritchie et al that acute colitis should be managed by gastroenterologists as the experience of general physicians in a district hospital is probably limited.

The low mortality after surgery reflects a policy of early intervention for any patient whose colitis fails to respond to medical management. Surgery was limited to a subtotal colectomy in severely ill patients, but proctocolectomy was more commonly carried out. Ileorectal anastomosis was reserved for a few carefully chosen patients who were reluctant to have an ileostomy. No pouches were performed, but in three patients the rectal stump was left so that this could be considered in the future. Infection was the main postoperative complication.

This retrospective audit shows the results of the routine management of acute colitis in one health district over a 10 year period

Operations performed on patients with acute colitis (numbers of patients given)

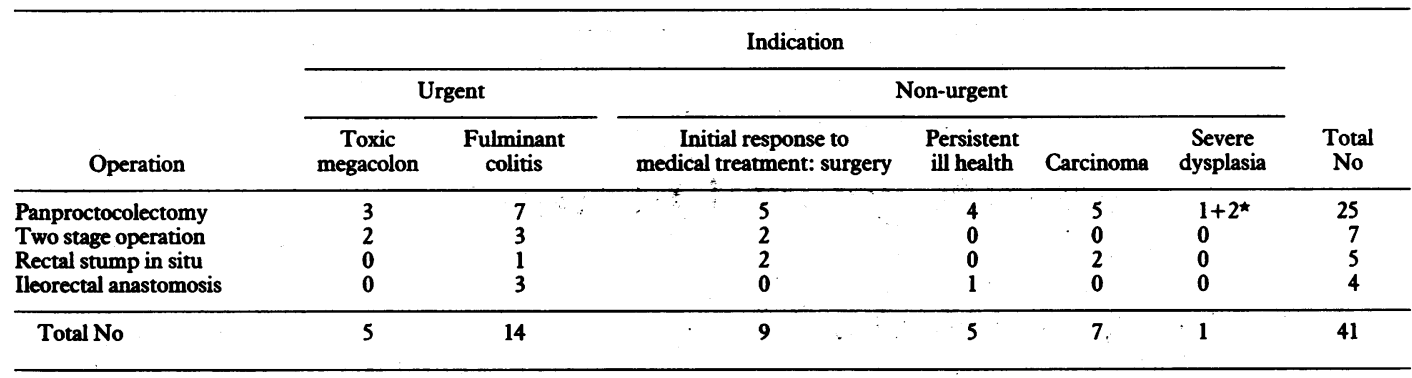

^Two patients had dysplasia and persistent ill health.

brachial plexus lesion (one), cholestatic jaurdice (one), and retrovaginal fistula before the rectal stump was removed (one). Three patients had small bowel obstructions within one year of surgery, and one had a further operation. The only long term complication was failure of ejaculation in one patient after the rectal stump was removed.

\section{Discussion}

Previous reports from England have indicated a high mortality rate for ulcerative colitis in district hospitals: an $18.4 \%$ mortality rate in 141 patients who were treated with surgery, over $50 \%$ in those who required urgent surgery, ${ }^{1}$ and $4.5 \%$ in 110 patients with acute colitis. ${ }^{3}$ In teaching centres the mortality has been virtually nil. ${ }^{23}$ As a result of those reports, a greater awareness of the dangers of acute colitis, and the presence of medical and surgical gastroenterologists in all district hospitals it is likely that the mortality from acute colitis in district hospitals has been reduced. The results of this study confirm that the mortality in one district was the same as that reported from teaching centres, with no deaths among 114 patients admitted with acute colitis. The proportion of patients whose colitis was undiagnosed before admission with acute colitis $(41 \%)$ is similar to that reported by Buckell and Lennard-Jones in 22 district hospitals (38\%), ${ }^{3}$ but the average age was higher in our study -48 years (range 13-93 years) compared with 39.5 years (range 11-86 years). The improved mortality, therefore, is likely to be due to changes in management rather than differences in groups of patients.

The proportion of patients who required urgent surgical treatment ( $20 \%$ of 96 patients) is also the same as reported by Buckell and Lennard-Jones (19\% of 119 patients). ${ }^{3}$ Similarly, the proportion of all patients who underwent surgery in this series (41 of 313 patients) is in the midrange of surgical rates reported in other series. ${ }^{7-12}$ It is surprising that our figures differ from those of Ritchie et $a l$, whose second survey was performed during the early part of during which there were no important advances in the management of patients with ulcerative colitis. The improvement in mortality compared with that reported previously from district general hospitals indicates that applying established methods of treatment has a profound effect on the outcome of acute ulcerative colitis.

We thank all the physicians and surgeons who allowed us to examine the clinical details of their cases and include them in the study; Dr W Gray and Dr M Turner for giving us the histopathology results; Mrs D Cox for help putting the data into the computer and typing the manuscript; and Micromed for the loan of their research software.

\section{References}

1 Ritchie JK. Ileostomy and excisional surgery for chronic inflammatory disease of the colon: a survey of one hospital region. Gut 1971;12:528-40.

2. Truelove SC, Willoughby CP, Lee EG, Kettlewell MGW. Further experience in the treatment of ulcerative colitis. Lancet 1978;ii:1086-8.

3 Buckell NA, Lennard-Jones JE. How district hospitals see acute colitis. Lancet 1979;ii:1226-9.

4 Ritchie JK, Ritchie SM, McIntyre PB, Marks CG. Management of severe acute colitis in district hospitals. $\mathcal{F} R$ Soc Med 1984;77:465-71.

Truelove SC, Jewell DP. Intensive intravenous regimen for severe attacks of ulcerative colitis. Lancet 1974; i:1067-70.

6 Truelove SC, Witts LJ. Cortisone in ulcerative colitis. Final report on a therapeutiç trial. BrMed $f$ 1955;ii:1041-8.

7 Edwards FC, Truelove SC. The course and prognosis of ulcerative colitis. Part I and II. Short and long term prognosis. Gut 1963;4:299-315.

8 Edwards FC, Truelove SC. The course and prognosis of ulcerative colitis. Part III and IV. Complications and carcinoma of the colon. Gut 1964;5:1-22.

9 Watts JM, DeDomball FT, Watkinson G, Goligher JC. Early course of ulcerative colitis. Gu 1966;7:16-31.

10 Watts JM, DeDomball FT, Watkinson G, Goligher JC. Long term prognosis of ulcerative colitis. BrMed F 1966; i:1447-53.

11 Bonnevie O, Binder V, Anthonisen P, Riis P. The prognosis of ulcerative colitis. Scand f Gastroenterol 1974;9:81-91.

12 Gyde S, Prior P, Dew MJ, Saunders V, Waterhouse JAH, Allan RN. Mortality in ulcerative colitis. Gastroenterology 1982;83:36-43. 